\title{
A lithium-oxygen battery based on lithium superoxide
}

Jun $\mathrm{Lu}^{1 *}$, Yun Jung Lee ${ }^{2 *}$, Xiangyi Luo ${ }^{3,4 *}, \mathrm{Kah}_{\mathrm{C}}$ Chun Lau ${ }^{3 *}$, Mohammad Asadi ${ }^{5 *}$, Hsien-Hau Wang ${ }^{3}$, Scott Brombosz ${ }^{3}$, Jianguo Wen ${ }^{6}$, Dengyun Zhai ${ }^{1}$, Zonghai Chen ${ }^{1}$, Dean J. Miller ${ }^{6}$, Yo Sub Jeong ${ }^{2}$, Jin-Bum Park ${ }^{2}$, Zhigang Zak Fang ${ }^{4}$, Bijandra Kumar ${ }^{7}$, Amin Salehi-Khojinn ${ }^{5}$, Yang-Kook Sun², Larry A. Curtiss ${ }^{3} \&$ Khalil Amine ${ }^{1}$

Batteries based on sodium superoxide and on potassium superoxide have recently been reported ${ }^{1-3}$. However, there have been no reports of a battery based on lithium superoxide $\left(\mathrm{LiO}_{2}\right)$, despite much research ${ }^{4-8}$ into the lithium-oxygen $\left(\mathrm{Li}-\mathrm{O}_{2}\right)$ battery because of its potential high energy density. Several studies ${ }^{9-16}$ of $\mathrm{Li}-\mathrm{O}_{2}$ batteries have found evidence of $\mathrm{LiO}_{2}$ being formed as one component of the discharge product along with lithium peroxide $\left(\mathrm{Li}_{2} \mathrm{O}_{2}\right)$. In addition, theoretical calculations have indicated that some forms of $\mathrm{LiO}_{2}$ may have a long lifetime ${ }^{17}$. These studies also suggest that it might be possible to form $\mathrm{LiO}_{2}$ alone for use in a battery. However, solid $\mathrm{LiO}_{2}$ has been difficult to synthesize in pure form ${ }^{18}$ because it is thermodynamically unstable with respect to disproportionation, giving $\mathrm{Li}_{2} \mathrm{O}_{2}$ (refs 19, 20). Here we show that crystalline $\mathrm{LiO}_{2}$ can be stabilized in a $\mathrm{Li}-\mathrm{O}_{2}$ battery by using a suitable graphene-based cathode. Various characterization techniques reveal no evidence for the presence of $\mathrm{Li}_{2} \mathrm{O}_{2}$. A novel templating growth mechanism involving the use of iridium nanoparticles on the cathode surface may be responsible for the growth of crystalline $\mathrm{LiO}_{2}$. Our results demonstrate that the $\mathrm{LiO}_{2}$ formed in the $\mathrm{Li}-\mathrm{O}_{2}$ battery is stable enough for the battery to be repeatedly charged and discharged with a very low charge potential (about 3.2 volts). We anticipate that this discovery will lead to methods of synthesizing and stabilizing $\mathrm{LiO}_{2}$, which could open the way to high-energy-density batteries based on $\mathrm{LiO}_{2}$ as well as to other possible uses of this compound, such as oxygen storage.

The crystalline $\mathrm{LiO}_{2}$ reported here was made electrochemically using a cathode based on reduced graphene oxide (rGO) with added iridium (Ir) nanoparticles. Initially graphene oxide (GO) was prepared by a modified Hummer's method ${ }^{21,22}$. The Ir-rGO composite was then made by a hydrothermal reduction method and characterized (Supplementary Fig. 2). Scanning electron microscopy (SEM) images of the pristine rGO and Ir-rGO composite (Fig. 1a and b, respectively) reveal porous three-dimensional (3D) networks of rGO composed of wrinkled 2D rGO sheets. Figure $1 \mathrm{c}$ and d shows transmission electron microscopy (TEM) images of the Ir nanoparticles on rGO, indicating that the well-dispersed Ir nanoparticles decorated on rGO are very small $(<2 \mathrm{~nm})$, with evidence for the presence of some small $\mathrm{Ir}$ clusters (circled in Fig. 1d). A backscattering image (Supplementary Fig. 1) shows some scattered larger Ir particles of about $500 \mathrm{~nm}$ in size, which may be due to agglomeration of the smaller nanoparticles, and fast Fourier transform analysis of high-resolution (HR)-TEM images (Supplementary Fig. 1) show that the nanoparticles are Ir. An X-ray photoemission spectroscopy (XPS) analysis (Supplementary Fig. 1) indicates the Ir surface is only partially oxidized.

The performance of the rGO and Ir-rGO cathodes was examined using a Swagelok-type cell composed of a lithium metal anode, electrolyte ( $1 \mathrm{M} \mathrm{LiCF}_{3} \mathrm{SO}_{3}$ in tetraethylene glycol dimethyl ether (TEGDME)) impregnated into a glass fibre separator, and a porous cathode. A current density of $100 \mathrm{~mA} \mathrm{~g}^{-1}$ was used for both discharge and charge, and the cell was run with a capacity limit of $1,000 \mathrm{~mA} \mathrm{~h}^{-1}$ to avoid side reactions. The specific capacity $\left(\mathrm{mA} \mathrm{h} \mathrm{g}^{-1}\right)$ and the current density $\left(\mathrm{mAg}^{-1}\right)$ are based on the active materials of the $\mathrm{O}_{2}$ electrodes. Figure $2 \mathrm{a}$ and $\mathrm{b}$ shows voltage profiles for the $\mathrm{Ir}-\mathrm{rGO}$ and $\mathrm{rGO}$ cathode architectures, respectively. The Ir-rGO discharge product shows a very low charge potential of $\sim 3.2 \mathrm{~V}$ that rises to $3.5 \mathrm{~V}$ over 40 cycles leading to more than $85 \%$ efficiency in this system (Fig. 2a). The voltage profile of the rGO cathode shows a much larger charge potential of $\sim 4.2 \mathrm{~V}$ with a lower efficiency of $\sim 67 \%$ (Fig. $2 \mathrm{~b}$ ).

The discharge product resulting from the Ir-rGO cathode was examined using SEM, differential electrochemical mass spectroscopy (DEMS), high-energy X-ray diffraction (HE-XRD), TEM and Raman spectroscopy with the results shown in Figs 2 and 3. The SEM image in Fig. $2 c$ shows the Ir-rGO cathode after discharge $(\sim 2.75 \mathrm{~V})$ from the first cycle $\left(1,000 \mathrm{~mA} \mathrm{~h}^{-1}\right.$ capacity). This image indicates that the discharge product resulting from the Ir-rGO-based cathode consists mainly of nanoparticles with needle- or rod-like morphology, although the presence of other shapes such as cubic cannot be ruled out. This needle- or rod-like morphology is also observed in the TEM image of a part of the discharge product, which appears to be on the surface of the Ir-rGO nanostructures (Fig. 2c inset). An SEM image after charging shows that the nanoparticles have disappeared (Supplementary Fig. 3). The discharge product from the rGO-based cathode has a range of morphologies, including toroids and nanoparticles (Supplementary Fig. 3). The Ir-rGO discharge product produced by a current density of $100 \mathrm{~mA} \mathrm{~g}^{-1}$ was characterized by DEMS during the first charging cycle by on-line monitoring of the number of evolved $\mathrm{O}_{2}$ molecules. The experiment was performed using high current densities $\left(1,000 \mathrm{~mA} \mathrm{~g}^{-1}\right.$ and $\left.640 \mathrm{~mA} \mathrm{~g}^{-1}\right)$ for charging to enable measurement of the evolved $\mathrm{O}_{2}$. The DEMS results at the higher current density are shown in Fig. 2d. Analysis of the data in Fig. 2d gives an average $\mathrm{O}_{2}$ formation rate of $1.3 \times 10^{-9} \mathrm{~mol} \mathrm{~s}^{-1}$, resulting in an $\mathrm{e}^{-} / \mathrm{O}_{2}$ ratio of 1.00 . A similar (1.00) $\mathrm{e}^{-} / \mathrm{O}_{2}$ ratio was also obtained for the experiment with a current density of $640 \mathrm{mAg}^{-1}$ (Supplementary Fig. 18). Additionally, negligible amounts of $\mathrm{CO}_{2}$ and $\mathrm{H}_{2}$ gases were generated during the DEMS experiments (Fig. 2d and Supplementary Fig. 18). A DEMS experiment was also carried out during discharge, and gave an $\mathrm{e}^{-} / \mathrm{O}_{2}$ ratio of 1.02 (Supplementary Fig. 18, Supplementary Table 3). These results are consistent with $\mathrm{LiO}_{2}$ as the main discharge product, and provide evidence for the absence of other products (for example, $\mathrm{Li}_{2} \mathrm{O}_{2}$, $\mathrm{LiOH}$ and $\mathrm{Li}_{2} \mathrm{CO}_{3}$ ). The DEMS results for $\mathrm{LiO}_{2}$ are similar to DEMS measurements on a $\mathrm{NaO}_{2}$ battery that gave an $\mathrm{e}^{-} / \mathrm{O}_{2}$ ratio of 1.00 for discharge and 1.02 for charge $e^{2}$.

\footnotetext{
${ }^{1}$ Chemical Sciences and Engineering Division, Argonne National Laboratory, Argonne, Illinois 60439, USA. ²Department of Energy Engineering, Hanyang University, Seoul 133-791, South Korea. ${ }^{3}$ Materials Science Division, Argonne National Laboratory, Argonne, Illinois 60439, USA. ${ }^{4}$ Department of Metallurgical Engineering, University of Utah, Salt Lake City, Utah 84112, USA.

${ }^{5}$ Department of Mechanical and Industrial Engineering, University of Illinois at Chicago, Chicago, Illinois 60607, USA. ${ }^{6}$ Center for Nanoscale Materials, Argonne National Laboratory, Argonne, Illinois 60439, USA. ${ }^{7}$ Conn Center for Renewable Energy Research, University of Louisville, Louisville, Kentucky 40292, USA.

*These authors contributed equally to this work.
} 
a

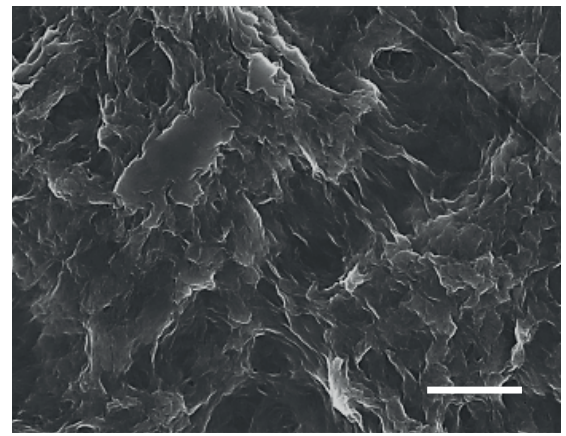

c

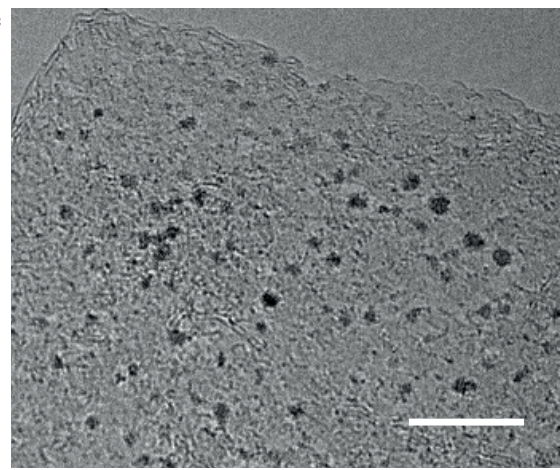

Figure $1 \mid$ Morphology of Ir-rGO. a, SEM image of pristine rGO

powder. b, SEM image of Ir-rGO composite. $\mathbf{c}, \mathbf{d}$, TEM images of Ir-rGO composite, showing Ir nanoparticles less than $2 \mathrm{~nm}$ in size. The circle in
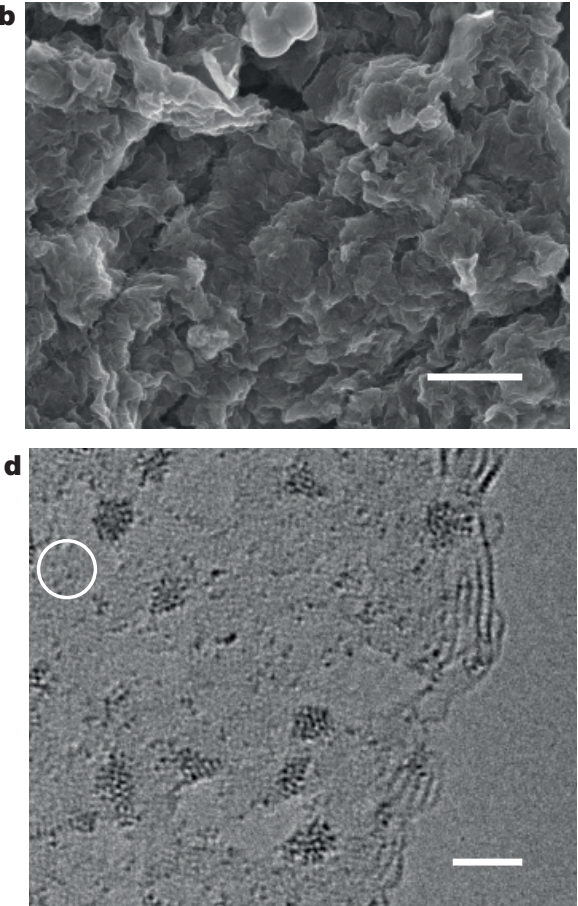

d shows some small Ir atomic clusters. Scale bars: a, b, $1 \mu \mathrm{m} ; \mathbf{c}, 10 \mathrm{~nm}$; d, $2 \mathrm{~nm}$. There are also some scattered large Ir agglomerates on the rGO (see Supplementary Fig. 1).
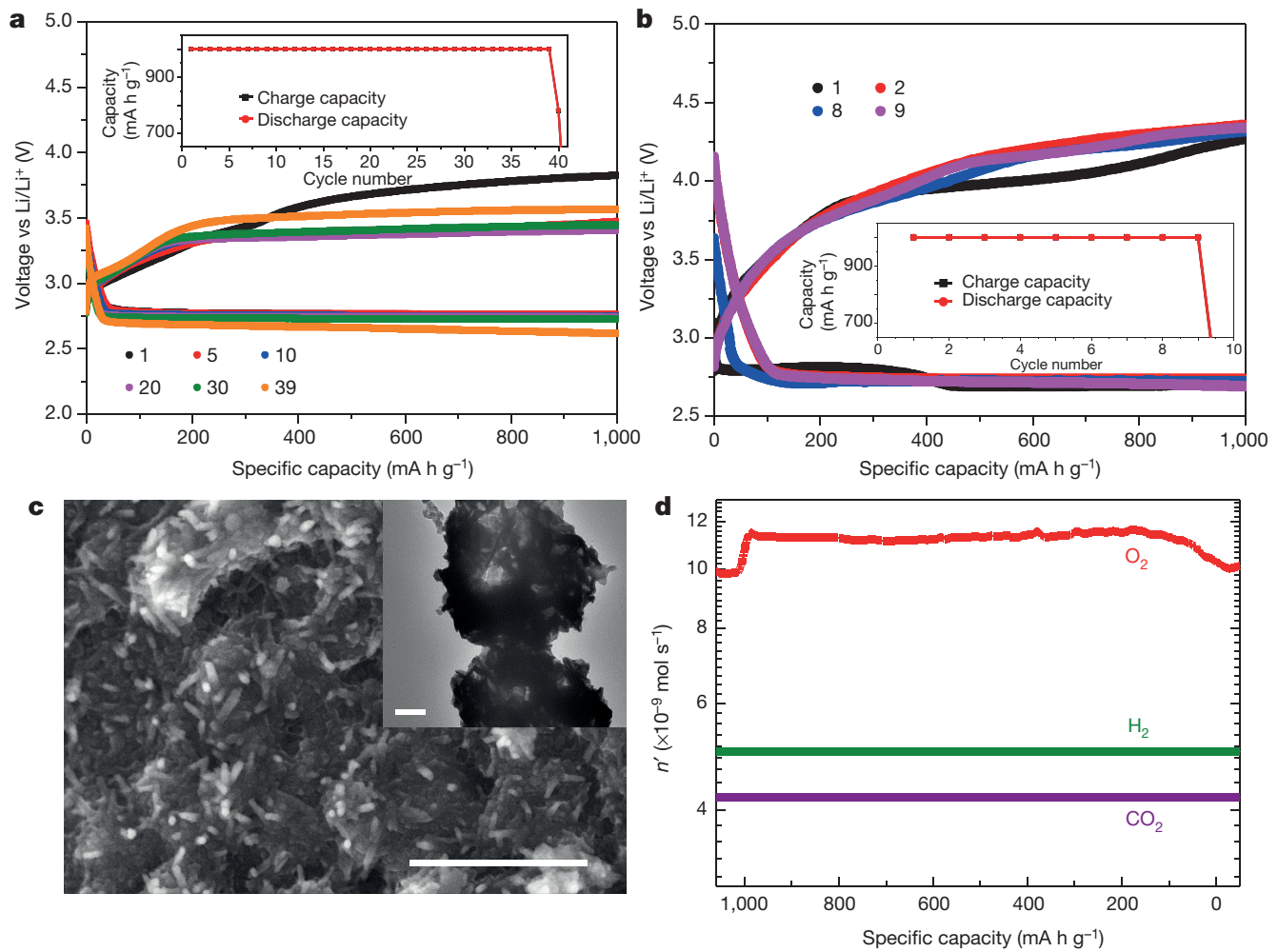

Figure 2 | Electrochemical tests and discharge products. a, Voltage profiles of the Ir-rGO cathode (see also Supplementary Fig. 6). Cycle number of voltage plot is given by the colour of the plotting symbol (see key). Inset shows capacity as a function of cycle number. $\mathbf{b}$, Voltage profiles of the rGO cathode. Cycle number of voltage plot is given by the colour of the plotting symbol (see key). Inset shows capacity as a function of cycle number. c, Main panel, SEM image of discharge product on Ir-rGO (scale bar, $1 \mu \mathrm{m}$ ); inset, TEM image of discharge product on

Ir-rGO (scale bar, $200 \mathrm{~nm}$ ). Both main panel and inset are from the first discharge with a current density of $100 \mathrm{mAg}^{-1}$, and capacity control of $1,000 \mathrm{mAh} \mathrm{g}^{-1}$. d, DEMS profile showing $\mathrm{O}_{2}, \mathrm{H}_{2}$ and $\mathrm{CO}_{2}$ gases released ( $n^{\prime}$ is the number of moles per second) from the cell during the charging process (at $1,000 \mathrm{~mA} \mathrm{~g}^{-1}$ current density) after the first discharge (at $100 \mathrm{mAg}^{-1}$ current density) to $1,000 \mathrm{~mA} \mathrm{~h} \mathrm{~g}^{-1}$ capacity (see Supplementary Information for details). 

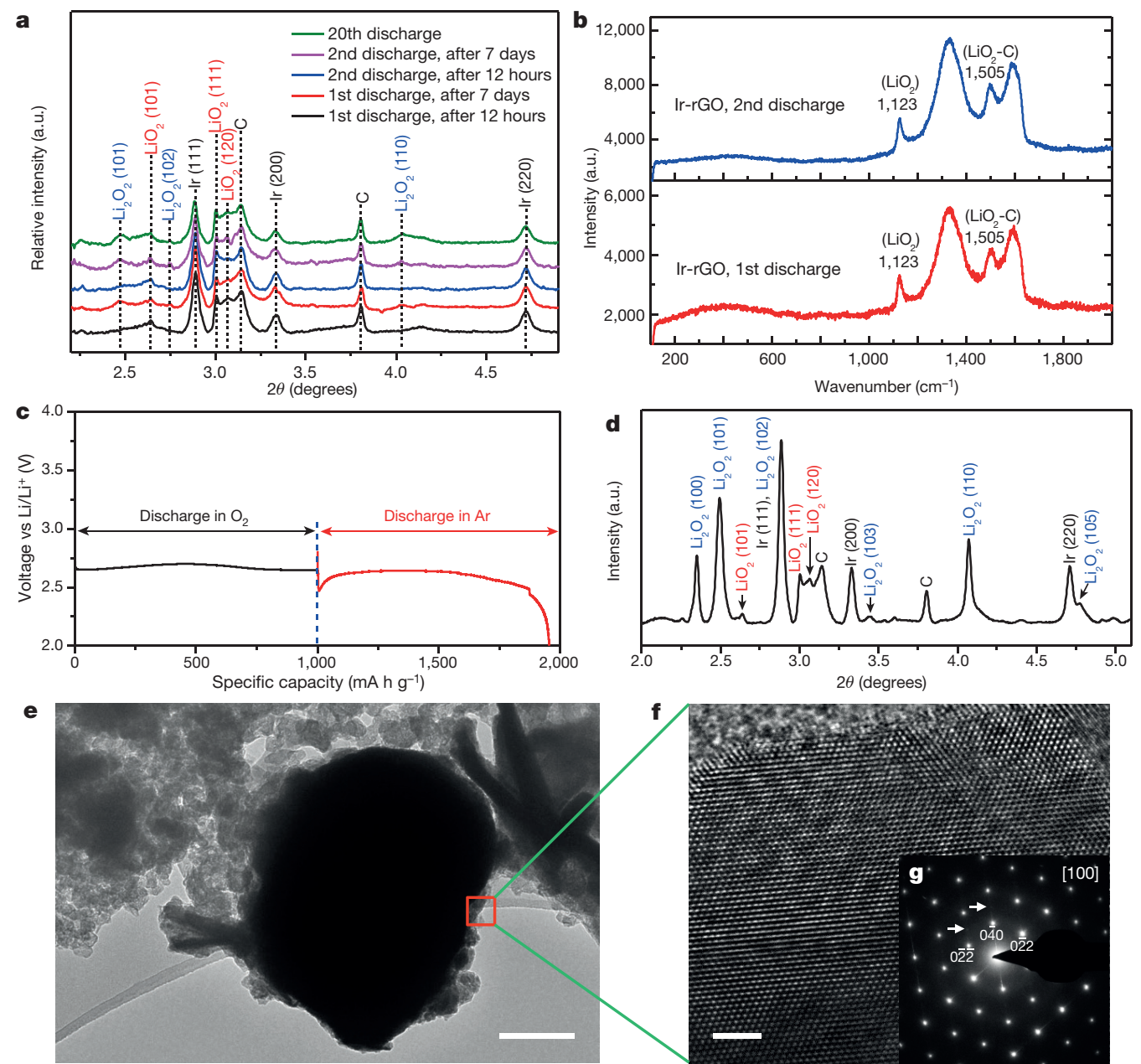

Figure 3 | Characterization of discharge products. a, HE-XRD patterns of discharge product on Ir-rGO as a function of ageing time. $\mathbf{b}$, Raman spectra of discharge product on Ir-rGO for first and second discharges. c, Voltage plots for Ir-rGO discharged first in $\mathrm{O}_{2}$ to a capacity of $1,000 \mathrm{~mA} \mathrm{~h}^{-1}$ and then discharged in Ar during which time it attained a capacity $956 \mathrm{~mA} \mathrm{~h} \mathrm{~g}^{-1}$; in the latter case, the electrolyte was purged with Ar before discharge (see Supplementary Fig. 16 for comparison with other

The HE-XRD pattern in Fig. 3a for the discharge product on the Ir-rGO cathode $\left(1,000 \mathrm{~mA} \mathrm{~h}^{-1}\right.$ capacity) during the first cycle shows peaks corresponding to crystalline $\mathrm{LiO}_{2}$ ((101), (111), (120)), and no evidence for peaks corresponding to $\mathrm{Li}_{2} \mathrm{O}_{2}$. The identification of the $\mathrm{LiO}_{2}$ peaks is based on a theoretical XRD pattern derived from the DFT (density functional theory)-predicted crystalline $\mathrm{LiO}_{2}$ structure (Supplementary Fig 4) from refs 19 and 23, as no experimental XRD pattern has been reported. The $\mathrm{LiO}_{2}$ structure is orthorhombic (Supplementary Fig. 4). For comparison, $\mathrm{NaO}_{2}$ is cubic at room temperature and orthorhombic at $<196 \mathrm{~K}$, whereas $\mathrm{KO}_{2}$ is tetragonal at room temperature. Some amorphous $\mathrm{LiO}_{2}$ cannot be ruled out on the basis of the XRD results. The standard XRD pattern of $\mathrm{Li}_{2} \mathrm{O}_{2}$ was used to determine the absence of $\mathrm{Li}_{2} \mathrm{O}_{2}$. The Raman spectra of the discharge product of the $\mathrm{Ir}-\mathrm{rGO}$ cathode in Fig. $3 \mathrm{~b}$ show the presence of a peak at $1,123 \mathrm{~cm}^{-1}$, consistent with the range of values that have been observed for superoxide stretching frequencies (Supplementary Table 1). It is also consistent with the Raman peak at $1,156 \mathrm{~cm}^{-1}$ observed ${ }^{1}$ for $\mathrm{NaO}_{2}$. There is also a peak at $1,505 \mathrm{~cm}^{-1}$ that has recently been attributed to the strong interaction between $\mathrm{LiO}_{2}$ and a graphitic carbon surface 9 . In contrast, the HE-XRD pattern (Supplementary Fig. 3) for the discharge product on the rGO cathode without Ir added (1,000 $\mathrm{mA} \mathrm{h}^{-1}$ capacity) during the first cycle shows peaks corresponding to both crystalline $\mathrm{LiO}_{2}((101),(111),(120))$ and $\mathrm{Li}_{2} \mathrm{O}_{2}$ ((101), (102), (103), (110)). Evidence for both $\mathrm{LiO}_{2}$ and $\mathrm{Li}_{2} \mathrm{O}_{2}$ cathode materials). d, HE-XRD pattern of cathode resulting from both discharges in c. e-g, TEM image of an Ir agglomerate after first discharge (e; scale bar, $200 \mathrm{~nm}$ ); f, HR-TEM image of boxed area in e (scale bar, $2 \mathrm{~nm}$ ); and $\mathbf{g}$, the corresponding electron diffraction pattern along the [100] zone axis giving evidence for the formation of $\mathrm{an}_{3} \mathrm{Ir}_{3} \mathrm{Li}$ intermetallic. The indices are diffraction vectors. Weak superstructure is observed as indicated by arrows.

components in the discharge product has also been reported in other studies $^{9-15}$, although none are based on XRD characterization, which is made possible by the use of high-energy X-rays at the Advanced Photon Source of Argonne National Laboratory. When the Ir-rGO cell is run to deep discharge of $2.2 \mathrm{~V}$ and $\sim 9,500 \mathrm{~mA} \mathrm{~h}^{-1}$ capacity, the HE-XRD data shows evidence for the presence of $\mathrm{LiO}_{2}, \mathrm{Li}_{2} \mathrm{O}_{2}$ and $\mathrm{LiOH}$ with a toroidal morphology (Supplementary Fig. 5).We also note that there have been some previous studies ${ }^{24,25}$ on rGO and rGO with $\mathrm{Au}$ nanoparticles that showed formation of $\mathrm{Li}_{2} \mathrm{O}_{2}$, but no report of $\mathrm{LiO}_{2}$ in a $\mathrm{Li}-\mathrm{O}_{2}$ cell.

Further evidence that the discharge product is $\mathrm{LiO}_{2}$ on the $\mathrm{Ir}-\mathrm{rGO}$ cathode was obtained by an experiment in which $\mathrm{Li}$ was electrochemically added to the discharge product without the presence of $\mathrm{O}_{2}$ (that is, $\mathrm{O}_{2}$ was replaced by $\mathrm{Ar}$ ). The voltage profile is shown in Fig. $3 \mathrm{c}$ for this discharge process, along with that of the initial discharge process (to $1,000 \mathrm{~mA} \mathrm{~h}^{-1} \mathrm{~g}$ ). The $\mathrm{HE}-\mathrm{XRD}$ of the resulting product with no $\mathrm{O}_{2}$ in the cell is shown in Fig. $3 \mathrm{~d}$ and reveals strong peaks from $\mathrm{Li}_{2} \mathrm{O}_{2}$, thus indicating a conversion of $\mathrm{LiO}_{2}$ to $\mathrm{Li}_{2} \mathrm{O}_{2}\left(\mathrm{Li}^{+}+\mathrm{e}^{-}+\mathrm{LiO}_{2} \rightarrow \mathrm{Li}_{2} \mathrm{O}_{2}\right)$ with $\sim 96 \%$ of the theoretical capacity for this reaction attained. This is evidence for a reaction involving one electron per $\mathrm{O}_{2}$ in the first cycle for $1,000 \mathrm{~mA} \mathrm{~h} \mathrm{~g}^{-1}$ capacity, and for no crystalline or amorphous $\mathrm{Li}_{2} \mathrm{O}_{2}$ forming on the initial capacity-limited discharge. In contrast, no significant capacity for discharge in Ar is observed for the rGO cathode when a similar procedure is performed. We have also carried 
a
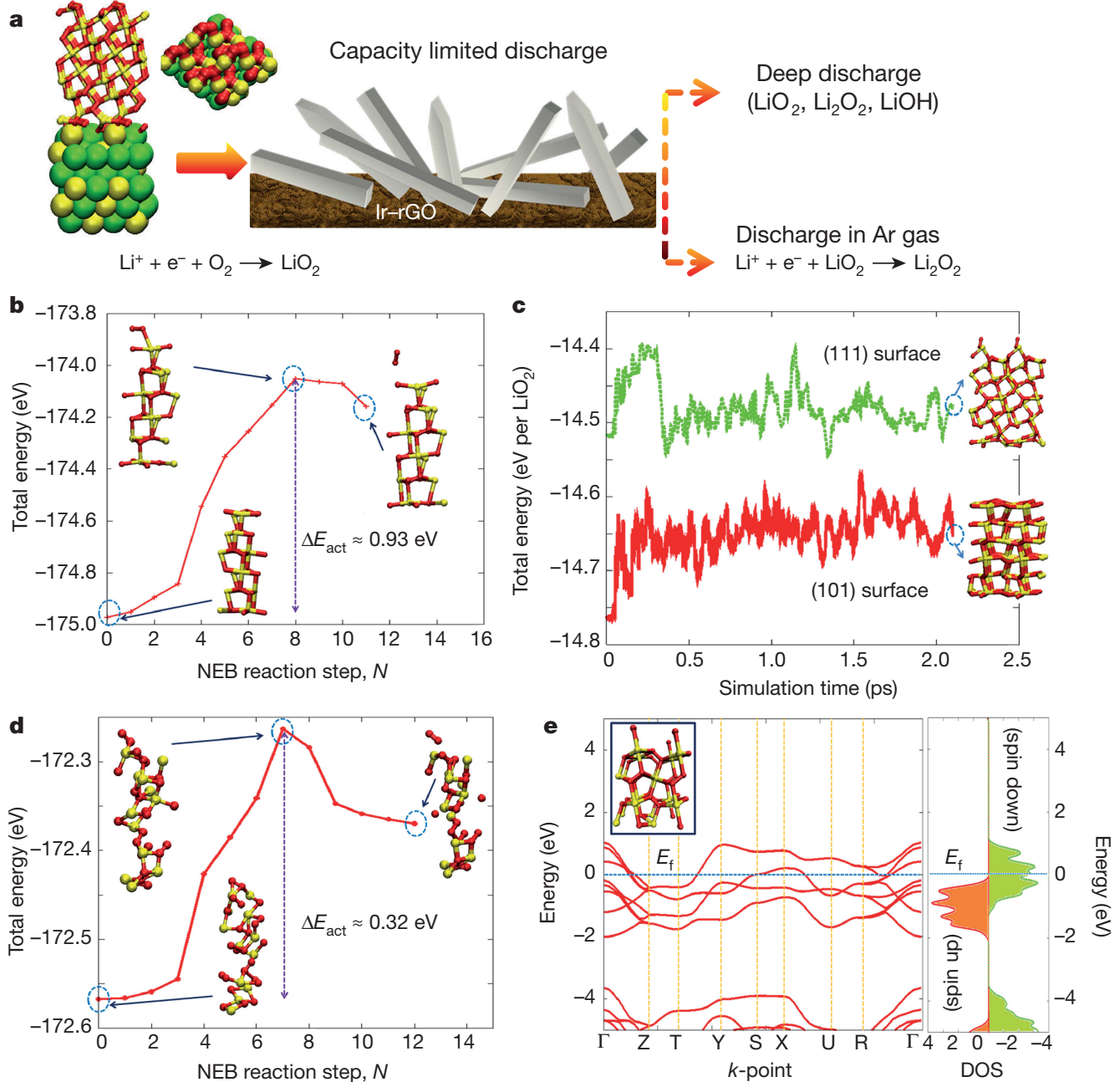

Figure 4 Density functional calculations. a, Schematic showing lattice match between $\mathrm{LiO}_{2}$ and $\mathrm{Ir}_{3} \mathrm{Li}$ (see also Supplementary Fig. 13) that may be responsible for the $\mathrm{LiO}_{2}$ discharge product found on the $\mathrm{Ir}-\mathrm{rGO}$ cathode. The two structures at left are the side- and top-views representing epitaxial growth of crystalline $\mathrm{LiO}_{2}$ in (111) orientation on a (121) facet of $\mathrm{Ir}_{3} \mathrm{Li}$ ( $\mathrm{Li}$ is yellow, $\mathrm{O}$ is red and $\mathrm{Ir}$ is green). The rod-like structures shown in the central figure are schematic representations of the crystalline $\mathrm{LiO}_{2}$ morphology observed in the experiment. Two subsequent electrochemical reactions that the $\mathrm{LiO}_{2}$ can undergo are shown on the right: that is, either further lithiation in the presence of Ar or further oxygen reduction in

the presence of oxygen. $\mathbf{b}$, DFT calculations of the barrier for desorption $\left(\Delta E_{\text {act }}\right)$ of an $\mathrm{O}_{2}$ molecule from the $(101) \mathrm{LiO}_{2}$ surface in vacuum from a Nudged Elastic Band (NEB) calculation as a function of number of reaction steps, $N$. c, AIMD simulations of $(111) \mathrm{LiO}_{2}$ and $(101) \mathrm{LiO}_{2}$ surfaces in vacuum at room temperature. d, DFT calculations of the barrier for desorption of an $\mathrm{O}_{2}$ molecule from an amorphous $\mathrm{LiO}_{2}$ surface in vacuum. e, DFT electronic band structure (left) and density of states (DOS) plot (right) of ferromagnetic bulk crystalline $\mathrm{LiO}_{2}$ close to the Fermi level $\left(E_{\mathrm{f}}\right)$ based on a spin polarized calculation with electronic spin-up and spin-down states shown. (See also Supplementary Fig. 17.)

out electron paramagnetic resonance (EPR) measurements, and find a signal that is consistent with the presence of $\mathrm{LiO}_{2}$ (Supplementary Fig. 7, Supplementary Table 2) in the initial discharge product.

The stability of the $\mathrm{LiO}_{2}$ was investigated by carrying out HE-XRD measurements on $\mathrm{Ir}-\mathrm{rGO}$ cathodes aged for different times in the presence of the electrolyte (Fig. 3a). After 12 hours at the end of both the first and second discharges the XRD patterns show only evidence for crystalline $\mathrm{LiO}_{2}$. When the discharge product is allowed to remain for seven days under the same conditions, both samples still show the signature of $\mathrm{LiO}_{2}$ along with the presence of crystalline $\mathrm{Li}_{2} \mathrm{O}_{2}$. Thus, the HE-XRD measurements indicate that the crystalline $\mathrm{LiO}_{2}$ formed with the Ir-rGO cathode is surprisingly stable for a relatively long period of time. Raman spectra (Supplementary Fig. 8) measured as a function of time exhibit a decreasing intensity of the peak at $1,123 \mathrm{~cm}^{-1}$ as a function of time, which is consistent with the HE-XRD results. In addition, $\mathrm{LiO}_{2}$ is still the dominant discharge product on the twentieth discharge cycle, indicating that $\mathrm{LiO}_{2}$ is stable enough that it can be repeatedly charged and discharged for about 40 cycles with a very low charge potential $(\sim 3.2 \mathrm{~V})$; this may open the way to a lithium-superoxide-based battery.

An explanation of the formation mechanism and stability of the $\mathrm{LiO}_{2}$ found in this study requires an understanding of the growth and nucleation process, which is quite complex and beyond the scope of the present study. However, our results are consistent with mechanisms proposed in other recent studies. Some insight can be obtained from a postulated mechanism for the nucleation and growth of discharge products from various size-specific Ag clusters decorating carbon cathodes in a $\mathrm{Li}-\mathrm{O}_{2}$ cell $^{7}$. In that case, the results are explained by a through-solution growth mechanism with sites for oxygen reduction reactions (ORRs) that are separate from the nucleation sites. Other researchers have also reported evidence for through-solution mechanisms ${ }^{26-29}$. In addition, the results of the Ag cluster study ${ }^{7}$ suggest that availability of good ORR sites promotes a through-solution mechanism involving nucleation and growth of $\mathrm{LiO}_{2}$ followed by disproportionation to $\mathrm{Li}_{2} \mathrm{O}_{2}$. Since both Ir and $\mathrm{rGO}$ are good ORR materials ${ }^{30,31}$, the Ir-rGO-based cathodes of the present study should result in a similar mechanism, that is, initial formation of $\mathrm{LiO}_{2}$.

The HE-XRD finding that $\mathrm{rGO}$ results in both $\mathrm{LiO}_{2}$ and $\mathrm{Li}_{2} \mathrm{O}_{2}$ in the discharge product can be accounted for by slow disproportionation. This explanation is supported by a recent theoretical study ${ }^{17}$ that has 
shown the possibility of fast and slow disproportionation processes for $\mathrm{LiO}_{2}$ depending on the $\mathrm{LiO}_{2}$ cluster size. In addition, experimental evidence for slow disproportionation has been found in studies of $\mathrm{Li}-\mathrm{O}_{2}$ cell discharge products based on an activated carbon cathode $\mathrm{e}^{10}$. In contrast, the present $\mathrm{HE}-\mathrm{XRD}$ results showing that only $\mathrm{LiO}_{2}$ is present in the case of the Ir-rGO-based cathode material suggest that disproportionation is suppressed.

The formation of only $\mathrm{LiO}_{2}$ in the case of the present Ir-rGO cathode may be due to some aspect of that cathode that favours nucleation and growth of largely the crystalline $\mathrm{LiO}_{2}$ phase, which prevents disproportionation (see theoretical calculations below). In the case of Ir-rGO, we noticed the formation of an $\mathrm{Ir}_{3} \mathrm{Li}$ intermetallic compound on the large Ir agglomerates seen in the backscattering image (Supplementary Fig. 1), as shown Fig. 3f and g). We also noticed that some nanoparticles (needle or rod-like) are formed on the surface of these agglomerates during the first discharge (Fig. 3e). We note that the $\operatorname{Ir}_{3} \mathrm{Li}$ intermetallic compound has an orthorhombic lattice, a similar crystallographic lattice ${ }^{32}$ to that of $\mathrm{LiO}_{2}$. It is possible that it may act as a template for growth of the crystalline $\mathrm{LiO}_{2}$, as has been found in template-controlled nucleation and growth of other crystalline materials ${ }^{33}$. We carried out DFT calculations on the interface between $\mathrm{LiO}_{2}$ and $\mathrm{Ir}_{3} \mathrm{Li}$, and found that some crystalline faces had good lattice matches (Supplementary Fig. 13), as would be required for epitaxial growth of crystalline $\mathrm{LiO}_{2}$. There may be other intermetallic compounds that exhibit similar behaviour and will be the subject of further study. The schematic in Fig. 4 summarizes the novel templating process that may be responsible for the $\mathrm{LiO}_{2}$ discharge product found for the Ir-rGO cathode material and the subsequent electrochemical reactions that it can undergo, that is, either further lithiation or further oxygen reduction. In contrast, the rGO cathode, which does not include Ir nanoparticles, probably has a different nucleation and growth mechanism resulting in a discharge product composed of both $\mathrm{LiO}_{2}$ and $\mathrm{Li}_{2} \mathrm{O}_{2}$.

The kinetic stability of crystalline and amorphous $\mathrm{LiO}_{2}$ was investigated using $a b$ initio molecular dynamics (AIMD) and DFT calculations with the results shown in Fig. 4. The disproportionation rate will depend on several factors. One factor is the rate at which the $\mathrm{O}_{2}$ leaves the surface. The DFT results in Fig. $4 \mathrm{~b}$ indicate that the initial step of $\mathrm{O}_{2}$ leaving the crystalline surface into vacuum has a barrier of $\sim 0.9 \mathrm{eV}$ based on a low-energy $\mathrm{LiO}_{2}$ surface. Figure $4 \mathrm{c}$ shows that crystalline $\mathrm{LiO}_{2}$ surfaces (that is, (101) and (111)) are thermally stable in vacuum at room temperature. For an amorphous surface, the barrier $(\sim 0.3 \mathrm{eV})$ is less than for the crystalline surface (Fig. $4 \mathrm{~d})$. From AIMD simulations, the presence of some solvent molecules adsorbed on the amorphous $\mathrm{LiO}_{2}$ surface reduces $\mathrm{O}_{2}$ desorption (Supplementary Fig. 14). This suggests that solvent on the $\mathrm{LiO}_{2}$ surface could further suppress disproportionation of the crystalline phase. The electrolyte effect on disproportionation was investigated by allowing a sample from a $1,000 \mathrm{~mA} \mathrm{~h}^{-1}$ discharge to age for $24 \mathrm{~h}$ in vacuum. Characterization of the sample by Raman spectroscopy, discharge in $\mathrm{Ar}$, and charge potential shows a significant decrease of $\mathrm{LiO}_{2}$ signature after ageing in vacuum, indicating that kinetics plays an important role in stabilizing the $\mathrm{LiO}_{2}$ (Supplementary Fig. 15)

The Ir-rGO cathode also exhibits a low charge potential, which may be due to several factors. As shown in Fig. 4e, crystalline $\mathrm{LiO}_{2}$ is a half-metal (on the basis of density functional calculations) and, thus, will have good electronic conduction, in contrast to insulating bulk $\mathrm{Li}_{2} \mathrm{O}_{2}$. Another factor is that $\mathrm{Ir}$ is known to be a good oxygen evolution catalyst ${ }^{31}$ and interacts strongly with $\mathrm{LiO}_{2}$ to form a good interface for electrical contact. These properties may explain why the discharge product formed on just rGO has a large charge potential, that is, it lacks the Ir nanoparticles. The $\mathrm{Li}-\mathrm{O}_{2}$ cell based on $\mathrm{Ir}-\mathrm{rGO}$ cathode material also can cycle 40 or more times (Supplementary Fig. 9) before failure, similar to what has been found for $\mathrm{Li}_{2} \mathrm{O}_{2}$-based $\mathrm{Li}-\mathrm{O}_{2}$ cells, indicating that the lithium superoxide is not any more reactive towards the electrolyte than lithium peroxide. In addition, the low charge potential will lead to less side reactions. The failure of the cell could be due to oxygen crossover to the anode resulting in the anode being converted to $\mathrm{LiOH}$, as evidenced by the corrosion of the anode (Supplementary Fig. 10) and, possibly the poisoning of Ir metal catalyst with cycling. When the cycled Li anode is replaced by a new anode, the cell cycles another 30 times (Supplementary Fig. 10).

The evidence presented here indicates that a $\mathrm{Li}-\mathrm{O}_{2}$ electrochemical cell based on $\mathrm{LiO}_{2}$ discharge product is possible with a reasonable cycle life, very high efficiency, and a good capacity. The performance characteristics of the cell based on $\mathrm{LiO}_{2}$ are comparable to those of previously reported electrochemical cells based on $\mathrm{KO}_{2}$ (ref. 3 ) and on $\mathrm{NaO}_{2}$ (ref. 1), although some aspects-such as the charge and discharge potentials-differ. Problems with electrolyte stability and decomposition, as for the electrolytes used for other $\mathrm{Li}-\mathrm{O}_{2}$ systems, probably still remain, but they do not seem any worse than for those systems. There is little evidence of any side reactions in the Raman data for the first discharge cycle (Fig. 3b), or from Raman and Fourier transform infrared data after charging for up to 30 cycles (Supplementary Figs 11, 12), or from NMR data up to 20 cycles (Supplementary Fig. 12), although there could be decomposition products that are not detected. The Fourier transform infrared and Raman results also confirm that the discharge product is not present after charging.

In summary, we have reported evidence it is possible to have a one-electron discharge process that forms only $\mathrm{LiO}_{2}$ in a $\mathrm{Li}-\mathrm{O}_{2}$ electrochemical cell. This is different from the previous studies ${ }^{9-15}$ that have provided evidence for both $\mathrm{LiO}_{2}$ and $\mathrm{Li}_{2} \mathrm{O}_{2}$ in the discharge product of $\mathrm{Li}-\mathrm{O}_{2}$ batteries with some cathode and electrolyte materials, and from studies ${ }^{16}$ that have shown $\mathrm{LiO}_{2}$ can be present in solution during discharge. The evidence for the existence of the $\mathrm{LiO}_{2}$ comes from DEMS and HE-XRD data with no evidence for $\mathrm{Li}_{2} \mathrm{O}_{2}$ being present. The results of TEM and density functional calculations indicate that a novel templating growth mechanism involving the use of Ir nanoparticles may be responsible for the crystalline $\mathrm{LiO}_{2}$ growth. The $\mathrm{LiO}_{2}$ formed in this way is stable enough to be repeatedly charged and discharged with a very low charge overpotential.

Online Content Methods, along with any additional Extended Data display items and Source Data, are available in the online version of the paper; references unique to these sections appear only in the online paper.

\section{Received 1 October 2014; accepted 13 November 2015.}

Published online 11 January 2016.

1. Hartmann, P. et al. A rechargeable room-temperature sodium superoxide $\left(\mathrm{NaO}_{2}\right)$ battery. Nature Mater. 12, 228-232 (2012)

2. Hartmann, P. et al. A comprehensive study on the cell chemistry of the sodium superoxide $\left(\mathrm{NaO}_{2}\right)$ battery. Phys. Chem. Chem. Phys. 15, 11661-11672 (2013)

3. Ren, X. \& Wu, Y. A low-overpotential potassium-oxygen battery based on potassium superoxide. J. Am. Chem. Soc. 135, 2923-2926 (2013).

4. Lu, J. et al. A nanostructured cathode architecture for low charge overpotential in lithium-oxygen batteries. Nature Commun. 4, 2383 (2013).

5. Bruce, P. G., Freunberger, S. A., Hardwick, L. J. \& Tarascon, J.-M. Li-O 2 and Li-S batteries with high energy storage. Nature Mater. 11, 19-29 (2011).

6. Lu, J. et al. Aprotic and aqueous $\mathrm{Li}^{-} \mathrm{O}_{2}$ batteries. Chem. Rev. 114, 5611-5640 (2014).

7. Lu, J. et al. Effect of the size-selective silver clusters on lithium peroxide morphology in lithium-oxygen batteries. Nature Commun. 5, 4895 (2014).

8. Black, R., Lee, J.-H., Adams, B., Mims, C. A. \& Nazar, L. F. The role of catalysts and peroxide oxidation in lithium-oxygen batteries. Angew. Chem. Int. Edn 52, 392-396 (2013).

9. Zhai, D. et al. Raman evidence for late stage disproportionation in a $\mathrm{Li}_{-} \mathrm{O}_{2}$ battery. J. Phys. Chem. Lett. 5, 2705-2710 (2014).

10. Zhai, D. et al. Disproportionation in $\mathrm{Li}-\mathrm{O}_{2}$ batteries based on a large surface area carbon cathode. J. Am. Chem. Soc. 135, 15364-15372 (2013).

11. Yang, J. et al. Evidence for lithium superoxide-like species in the discharge product of a $\mathrm{Li}-\mathrm{O}_{2}$ battery. Phys. Chem. Chem. Phys. 15, 3764-3771 (2013).

12. Gittleson, F. S., Ryu, W.-H. \& Taylor, A. D. Operando observation of the gold-electrolyte interface in $\mathrm{Li}_{2} \mathrm{O}_{2}$ batteries. ACS Appl. Mater. Interfaces 6, 19017-19025 (2014).

13. Gittleson, F. S. et al. Raman spectroscopy in lithium-oxygen battery systems. ChemElectroChem 2, 1446-1457 (2015). 
14. Olivares-Marín, M. et al. Spatial distributions of discharged products of lithium-oxygen batteries revealed by synchrotron X-ray transmission microscopy. Nano Lett. 15, 6932-6938 (2015).

15. Ryu, W.-H., Gittleson, F. S., Schwab, M., Goh, T. \& Taylor, A. D. A mesoporous catalytic membrane architecture for lithium-oxygen battery systems. Nano Lett. 15, 434-441 (2015)

16. Schaltin, S., Vanhoutte, G., Wu, M., Bardé, F. \& Fransaer, J. A QCM study of ORR-OER and an in situ study of a redox mediator in DMSO for $\mathrm{Li}_{2} \mathrm{O}_{2}$ batteries. Phys. Chem. Chem. Phys. 17, 12575-12586 (2015).

17. Das, U., Lau, K. C., Redfern, P. C. \& Curtiss, L. A. Structure and stability of lithium superoxide clusters and relevance to $\mathrm{Li}-\mathrm{O}_{2}$ batteries. J. Phys. Chem. Lett. 5, 813-819 (2014).

18. Sangster, J. \& Pelton, A. D. The Li-O (lithium-oxygen) system. J. Phase Equilibria 13, 296-299 (1992).

19. Lau, K. C., Curtiss, L. A. \& Greeley, J. Density functional investigation of the thermodynamic stability of lithium oxide bulk crystalline structures as a function of oxygen pressure. J. Phys. Chem. C 115, 23625-23633 (2011)

20. Kang, S., Mo, Y., Ong, S. P. \& Ceder, G. A facile mechanism for recharging $\mathrm{Li}_{2} \mathrm{O}_{2}$ in $\mathrm{Li}_{-} \mathrm{O}_{2}$ batteries. Chem. Mater. 25, 3328-3336 (2013)

21. Hummers, W. S. \& Offeman, R. E. Preparation of graphitic oxide. J. Am. Chem. Soc. 80, 1339 (1958).

22. Xu, Y., Sheng, K., Li, C. \& Shi, G. Self-assembled graphene hydrogel via a one-step hydrothermal process. ACS Nano 4, 4324-4330 (2010).

23. Zhuravlev, Y. N. \& Obolonskaya, O. S. Structure, mechanical stability, and chemical bond in alkali metal oxides. J. Struct. Chem. 51, 1005-1013 (2010)

24. Kumar, S. Selvaraj, C. Munichandraiah, N. \& Scanlon, L. G. Gold nanoparticles anchored reduced graphene oxide as catalyst for oxygen electrode of rechargeable $\mathrm{Li}_{-} \mathrm{O}_{2}$ cells. RSC Adv. 3, 21706-21714 (2013).

25. Selvaraj, C., Kumar, S., Munichandraiah, N. \& Scanlon, L. G. Reduced graphene oxide-polypyrrole composite as a catalyst for oxygen electrode of high rate rechargeable Li-O 2 cells. J. Electrochem. Soc. 161, A554-A560 (2014).

26. Oh, S. H., Black, R., Pomerantseva, E., Lee, J.-H. \& Nazar, L. F. Synthesis of a metallic mesoporous pyrochlore as a catalyst for lithium $-\mathrm{O}_{2}$ batteries. Nature Chem. 4, 1004-1010 (2012).

27. Ren, X., Zhang, S. S., Tran, D. T. \& Read, J. Oxygen reduction reaction catalyst on lithium/air battery discharge performance. J. Mater. Chem. 21, 10118-10125 (2011).

28. Mitchell, R. R., Gallant, B. M., Shao-Horn, Y. \& Thompson, C. V. Mechanisms of morphological evolution of $\mathrm{Li}_{2} \mathrm{O}_{2}$ particles during electrochemical growth. J. Phys. Chem. Lett. 4, 1060-1064 (2013).

29. Ottakam Thotiyl, M. M., Freunberger, S. A., Peng, Z. \& Bruce, P. G. The carbon electrode in nonaqueous $\mathrm{Li}_{-} \mathrm{O}_{2}$ cells. J. Am. Chem. Soc. 135, 494-500 (2013).

30. Bikkarolla, S. K., Cumson, P., Joseph, P. \& Papakonstantinou, P. Oxygen reduction reaction in electrochemically reduced graphene oxide. Faraday Discuss. 173, 415-428 (2014).

31. Antolini, E. Iridium as catalyst and cocatalyst for oxygen evolution/reduction in acidic polymer electrolyte membrane electrolyzers and fuel cells. ACS Catal. 4, 1426-1440 (2014).
32. Donkersloot, H. C. \& Van Vucht, J. H. N. The crystal structure of IrLi, Ir 3 Li and $\mathrm{LiRh}_{3}$. J. Less Common Met. 50, 279-282 (1976).

33. Pouget, E. M. et al. The initial stages of template-controlled $\mathrm{CaCO}_{3}$ formation revealed by cryo-TEM. Science 323, 1455-1458 (2009)

Supplementary Information is available in the online version of the paper.

Acknowledgements This work was primarily supported by the US Department of Energy under contract DE-AC02-06CH11357 from the Vehicle Technologies Office, Department of Energy, Office of Energy Efficiency and Renewable Energy. We also acknowledge support from the Center for Electrochemical Energy Science (CEES), an Energy Frontier Research Center (EFRC) funded by the US Department of Energy, Office of Science, Office of Basic Energy Sciences (X-ray measurements and analysis). We also acknowledge support from the University of Illinois-Chicago Chancellor Proof of Concept Fund (DEMS measurements). We acknowledge the Conn Renewable Energy Research Center at the University of Louisville for providing the access to the DEMS equipment. We acknowledge grants of computer time through INCITE awards on the BlueGene/Q computer at Argonne National Laboratory and allocations on the CNM Carbon Cluster at Argonne National Laboratory and the LCRC Fusion Cluster at Argonne National Laboratory. Use of the Advanced Photon Source and the Electron Microscopy Center, Center for Nanoscale Materials was supported by the US Department of Energy, Office of Basic Energy Sciences, under contract no. DE-AC02-06CH11357. We acknowledge financial support from the Human Resources Development of the Korea Institute of Energy Technology Evaluation and Planning (KETEP) funded by the Korea government Ministry of Knowledge Economy (no. 20124010203310), and from the Basic Science Research Program (no. NRF-2014R1A2A1A1 1049801). We acknowledge C. Barile, R. Rooney, R. Assary and P. Redfern for discussions and help on the lithium superoxide reaction mechanism.

Author Contributions J.L. and K.A. designed the experiments; Y.J.L., J.-B.P. and Y.S.J. synthesized the cathode materials; J.L., D.J.M. and J.W. performed and analysed the TEM imaging experiments; J.L., X.L., L.A.C. and Z.C. performed and analysed the X-ray measurements; J.L., X.L., Z.Z.F., D.Z. and H.-H.W. tested the cathode materials; M.A., A.S.-K. and B.K. performed the DEMS measurements, H.-H.W., X.L. and S.B. performed the Raman, NMR, EPR and FTIR experiments, K.C.L. and L.A.C. were responsible for the theoretical computations. L.A.C., K.A. and Y.-K.S. supervised the project; L.A.C., J.L. and K.A. wrote the paper. All of the authors discussed the results and reviewed the manuscript.

Author Information Atomic coordinates for the $\mathrm{LiO}_{2}$ crystal structure from DFT can be obtained from the ICSD Database (http://www2.fiz-karlsruhe.de/icsd home.html). Reprints and permissions information is available at www.nature. $\mathrm{com} /$ reprints. The authors declare no competing financial interests. Readers are welcome to comment on the online version of the paper. Correspondence and requests for materials should be addressed to L.A.C. (curtiss@anl.gov) or K.A. (amine@anl.gov) or Y.-K.S. (yksun@hanyang.ac.kr). 


\section{METHODS}

Material preparation. Graphene oxide (GO) was prepared by a modified Hummers method ${ }^{21,22}$. Pristine reduced $\mathrm{GO}(\mathrm{rGO})$ was produced by reducing GO in polyol ${ }^{34}$. Specifically, a GO dispersion $\left(1 \mathrm{mg} \mathrm{ml}^{-1}\right)$ in ethylene glycol (EG) was first prepared with the aid of horn sonication for $1 \mathrm{~h}$. The solution $\mathrm{pH}$ was then adjusted to $\mathrm{pH} 13$ with $\mathrm{NaOH}$ ( $2.5 \mathrm{M}$ in EG). The reaction temperature was increased to $120^{\circ} \mathrm{C}$, and a reducing agent $\left(\mathrm{NaBH}_{4}\right)$ dissolved in $\mathrm{EG}$ was injected slowly. The solution was allowed to react for $1 \mathrm{~h}$ at this temperature and then cooled to room temperature. The precipitate was filtered, washed and dried under vacuum. The Ir-rGO composite was synthesized by a hydrothermal method. $\operatorname{IrCl}_{3} \bullet \mathrm{H}_{2} \mathrm{O}$ was added to $100 \mathrm{ml}$ aqueous $\mathrm{GO}$ solution $\left(0.67 \mathrm{mg} \mathrm{ml}^{-1}\right)$ with a weight ratio of $\mathrm{IrCl}_{3} \bullet \mathrm{H}_{2} \mathrm{O}$ to GO of 1.9:1. The mixture was stirred for $2 \mathrm{~h}$. The resulting solution was transferred to a Teflon-lined autoclave and there reacted hydrothermally at $180^{\circ} \mathrm{C}$ for $12 \mathrm{~h}$. The precipitate was filtered, washed and dried under vacuum. During hydrothermal treatment, Ir nanocrystals are obtained with simultaneous reduction of $\mathrm{GO}$ into $\mathrm{rGO}$, without addition of strong base.

After synthesis, the Ir-rGO and $\mathrm{rGO}$ powders were dried at $80^{\circ} \mathrm{C}$ under vacuum for $24 \mathrm{~h}$. To prepare the oxygen electrode, the $\mathrm{Ir}-\mathrm{rGO}$ and $\mathrm{rGO}$ were intimately mixed in an N-methyl-2-pyrrolidone (NMP) liquid and a polyvinylidene fluoride binder (PVDF) with a weight ratio of active ingredients to PVDF of 8:2. The slurry was coated onto a gas-diffusion layer (TGP-H-030 carbon paper, Torray) and dried for $12 \mathrm{~h}$ at $100^{\circ} \mathrm{C}$ under vacuum to remove the residual solvent.

Electrochemical testing. Electrochemical testing was carried out using a Swagelok-type cell composed of a lithium metal anode, electrolyte $\left(1 \mathrm{M} \mathrm{LiCF}_{3} \mathrm{SO}_{3}\right.$ in tetraethylene glycol dimethyl ether (TEGDME) impregnated into a glass fibre separator), and a porous cathode ( $7 / 16$ inch diameter). The cells were sealed except for the $\mathrm{Al}$ grid window that exposed the porous cathode to 1 bar $\mathrm{O}_{2}$ pressure. The electrochemical measurements were carried out using a MACCOR cycler. The discharge-charge performance was conducted in the voltage range of $2.2-4.5 \mathrm{~V}$ at a constant current density of $100 \mathrm{mAg}^{-1}$, and the cell was maintained in 1 bar $\mathrm{O}_{2}$ atmosphere to avoid any negative effects of humidity and $\mathrm{CO}_{2}$

Characterization techniques. The phase structures of the discharge products were identified using high-energy X-ray diffraction (HE-XRD) with a wavelength of $0.11165 \AA$, performed at beamline 11ID-C of Sector 11 at the Advanced Photon Source (APS) of Argonne National Laboratory. The X-ray specimens were sealed with Kapton tape as a protective film in the glove box to avoid any side reactions from the air. The HE-XRD patterns were collected in the transmission mode. During the course of the measurements, a high-energy X-ray beam hit the sample horizontally, and a 2D detector (Perkin Elmer large area detector) was used to collect the X-ray diffraction profiles using transmission mode. The $2 \mathrm{D}$ patterns were then integrated into conventional 1D patterns (intensity versus $2 \theta$ ) for final data analysis using Fit2d software.

Scanning transmission electron microscopy (TEM; JEOL JEM-2100F FEG FasTEM with an accelerating voltage of $80 \mathrm{kV}$ ) was employed to evaluate the morphology and particle size of the Ir catalysts and the discharge products on the porous cathodes. Spherical and chromatic aberration correction enables the microscope to reach the information limit, which is a resolution of $0.1 \mathrm{~nm}$ (measured by Young's fringes) at $80 \mathrm{kV}$. To prepare the TEM specimens, a dilute suspension was prepared by ultrasonically dispersing the samples in dimethyl ether for $5 \mathrm{~min}$, and a drop of the suspension was placed onto a copper grid and dried. Particle size histograms were generated from the TEM images using software ImageJ. Field-emission scanning electron microscopy (SEM, Hitachi S-4700) coupled with backscattering electron imaging (BSE) was employed to determine the morphology and estimate the particle size of Ir catalyst and discharge products.

Raman spectra of the discharged cathode were obtained using a Renishaw 2000 or inVia microscope spectrometer with a HeNe laser at an exciting wavelength of $633 \mathrm{~nm}$. The sample was loaded inside a glove box into a gas-tight Raman cell with a glass or quartz window. Raman spectrum collection was set up in a $180^{\circ}$ reflective mode. Roughly $10 \%$ of the maximum $13 \mathrm{~mW}$ laser intensity was applied. Collection time constant setting varied from $30 \mathrm{~s}$ to $\sim 100 \mathrm{~s}$.

Nuclear Magnetic Resonance (NMR) spectra were collected on a Bruker Avance III $500 \mathrm{MHz}(11.7 \mathrm{~T})$ spectrometer in deuterated tetrahydrofuran (THF-d8) or deuterium oxide $\left(\mathrm{D}_{2} \mathrm{O}\right)$. Battery samples were cycled the appropriate number of times before disassembly and rinsing with a deuterated solvent. For the samples in THF-d8, NMR samples were prepared entirely under an inert atmosphere. For samples in $\mathrm{D}_{2} \mathrm{O}$, the battery was disassembled under an inert atmosphere, removed from the glove box, immediately rinsed with $\mathrm{D}_{2} \mathrm{O}$, and sealed in an NMR tube. All $1 \mathrm{H}$-NMR collections were sampled for 128 scans, manually phased, and baseline corrected before peak integration. Data collection was performed using the Bruker Topspin software (v. 3.1). Data analysis used either TopSpin (v. 3.1) or SpinWorks (V4.1.0.0)
DEMS measurements were carried out to examine the type of discharge product by measuring the evolved oxygen $\left(\mathrm{O}_{2}\right)$ molecules during the charging process, as well as calculating the $\mathrm{e}^{-} / \mathrm{O}_{2}$ ratio. The experiments were performed using an HPR40 (Hiden Analytical) instrument directly connected to a customized Swagelok battery set-up.

Theoretical methods. To study the stability of the $\mathrm{LiO}_{2}$ system (that is, crystal, crystalline surfaces, amorphous-like thin film), its interface with a solvent and its surface growth on a intermetallic substrate (that is, $\operatorname{Ir}_{3} \mathrm{Li}$ ), we carried out Density Functional Theory (DFT) calculations with plane wave basis sets as implemented in the VASP code ${ }^{35,36}$. All the calculations were spin-polarized and carried out using the gradient corrected exchange-correlation functional of Perdew, Burke and Ernzerhof $(\mathrm{PBE})^{37}$ under the projector augmented wave (PAW) method, with plane wave basis sets up to a kinetic energy cutoff of $400 \mathrm{eV}$. The PAW method ${ }^{38}$ was used to represent the interaction between the core and valence electrons, and the Kohn-Sham valence states (that is, $1 s$ for $\mathrm{H}, 2 s$ for $\mathrm{Li}, 2 s 2 p$ for $\mathrm{C}$ and $\mathrm{O}$, $6 s 5 d$ for Ir) are expanded in plane wave basis sets. For the geometry optimization and Nudge Elastic Band calculations, the convergence criterion of the total energy was set to be within $1 \times 10^{-5} \mathrm{eV}$ for the $k$-point integration, and all the atoms and geometries were optimized until the residual forces became less than $1 \times 10^{-2} \mathrm{eV}^{-1}$. For the $\mathrm{LiO}_{2}$ crystal, the calculation was based on a mesh of $9 \times 9 \times 9$ in $k$-point grid. For both the crystalline and amorphous-like $\mathrm{LiO}_{2}$ thin film surfaces, a $k$-point grid of $6 \times 6 \times 1$ was used. For the $A b$ initio Molecular Dynamics (AIMD) simulations, all the calculations were carried out with plane wave basis sets up to a kinetic energy cutoff of $300 \mathrm{eV}$. For the simulations of $\mathrm{LiO}_{2}$ surface with some solvent molecules on it, the Van der Waals method of Grimme (that is, DFT-D2) ${ }^{39}$ was used throughout both the DFT and AIMD calculations. For the simulation of the solvent, a smaller ether solvent molecule, that is, dimethoxyethane (DME) was used instead of tetraethylene glycol dimethyl ether (TEGDME) in order to reduce the computational cost. To investigate the thermodynamic stability of the system at room temperature, all the structures from the DFT optimizations were then thermally equilibrated at $T=300 \mathrm{~K}$ using AIMD simulations based on an Nose-Hoover NVT-ensemble with a time step of $1 \mathrm{fs}$.

For the $a b$ initio prediction of Electron Paramagnetic Resonance (EPR) $g$-tensors of the crystalline solids $\mathrm{LiO}_{2}$ and $\mathrm{NaO}_{2}$, we have used the DFT plane wave code Quantum Espresso simulation package ${ }^{40}$ in which the Gauge-Including Projector Augmented Plane Wave (GIPAW) approach ${ }^{41}$ has been implemented. To be consistent with our VASP calculations, we employed the PBE functional and MartinsTroullier norm-conserving pseudopotentials generated by D Ceresoli (https://sites google.com/site/dceresoli/pseudopotentials). Throughout the simulation, a plane wave energy cutoff of $150 \mathrm{Ry}$ and $k$-point mesh $(9 \times 9 \times 9)$ was used. Only the $\mathrm{NaO}_{2}$ solid in Pnnm orthorhombic phase ${ }^{42}$ that is thermodynamically stable at low temperature was considered in our DFT EPR calculations. For the ab initio prediction of the EPR $g$-tensor of the $\mathrm{LiO}_{2}$ and $\mathrm{NaO}_{2}$ molecules, all the calculations were obtained using the Gaussian 09 code. The accuracy of the theoretical predictions are systematically tested using PBE and B3LYP functionals with the 6-31+G(2df,p) and aug-cc-PVQZ basis sets for direct comparison to the reported experimental $\mathrm{LiO}_{2}$ and $\mathrm{NaO}_{2}$ EPR g-tensors ${ }^{43,44}$.

Sample size. No statistical methods were used to predetermine sample size.

34. Ha, H.-W., Kim, I. Y., Hwang, S.-J. \& Ruoff, R. S. One-pot synthesis of platinum nanoparticles embedded on reduced graphene oxide for oxygen reduction in methanol fuel cells. Electrochem. Solid-State Lett. 14, B70-B73 (2011).

35. Kresse, G. \& Furthmüller, J. Efficiency of ab-initio total energy calculations for metals and semiconductors using a plane-wave basis set. Comput. Mater. Sci. 6, 15-50 (1996)

36. Kresse, G. \& Joubert, D. From ultrasoft pseudopotentials to the projector augmented-wave method. Phys. Rev. B 59, 1758-1775 (1999).

37. Perdew, J. P., Burke, K. \& Ernzerhof, M. Generalized Gradient Approximation made simple. Phys. Rev. Lett. 77, 3865-3868 (1996).

38. Blöchl, P. E. Projector augmented-wave method. Phys. Rev. B $\mathbf{5 0}$ 17953-17979 (1994)

39. Grimme, S. Semiempirical GGA-type density functional constructed with a long-range dispersion correction. J. Comput. Chem. 27, 1787-1799 (2006)

40. Giannozzi, P. et al. QUANTUM ESPRESSO: a modular and open-source software project for quantum simulations of materials. J. Phys. Condens. Matter 21, 395502 (2009)

41. Pickard, C. J. \& Mauri, F. First-principles theory of the EPR g tensor in solids: defects in quartz. Phys. Rev. Lett. 88, 086403 (2002).

42. Ziegler, M., Rosenfeld, M., Kaenzig, W. \& Fischer, P. Strukturuntersuchungen an Alkalihyperoxiden. Helvetica Physica Acta 49, 57-90 (1976)

43. Adrian, F. J., Cochran, E. L. \& Bowers, V. A. ESR spectra and structures of $\mathrm{NaSO}_{2}$ and $\mathrm{NaO}_{2}$. J. Chem. Phys. 59, 56-60 (1973)

44. Lindsay, D. M. \& Garland, D. A. ESR spectra of matrix-isolated lithium superoxide. J. Phys. Chem. 91, 6158-6161 (1987). 